\title{
Nuevos roles del líder político en programas televisivos de infoentretenimiento
}

\section{New job roles of the political leaders in infotainment television programs}
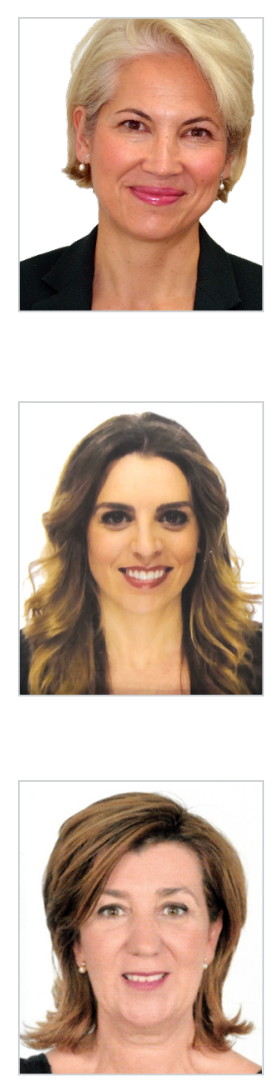

Marta Redondo García. Profesora Contratada Doctora en la Universidad de Valladolid. Es miembro del Grupo de Investigación Reconocido Nuevas Tendencias en Comunicación (NUTECO). Participa como investigadora en varios proyectos de ámbito nacional e internacional. Su labor investigadora se centra en el análisis de la penetración del sensacionalismo en los medios de comunicación, la ética periodística, el infoentretenimiento y la comunicación política. Es autora o coautora de una treintena de capítulos de libro y artículos publicados en revistas tales como: Comunicar, El Profesional de la Información, Revista Latina de Comunicación Social o Comunicación y Sociedad. Como profesional ha trabajado en diversos medios de comunicación: Antena 3, Televisión Española o Vía Digital, entre otros. Es Premio Extraordinario de Doctorado y Premio Internet de Periodismo de la Junta de Castilla y León.

Universidad de Valladolid, España

marta.redondo@hmca.uva.es

ORCID: 0000-0001-8143-465X

Marta Ventura Meneu. Doctoranda en la Universidad de Valladolid, realiza sus investigaciones en torno a las corrientes del infotainment y el politainment, dirigida por Marta Redondo y Salomé Berrocal. Licenciada en Comunicación Audiovisual y en Publicidad y RR.PP por la Universitat Jaume I de Castellón. Máster en Nuevas tendencias y procesos de innovación en comunicación por la Universitat Jaume I y Máster de Profesorado en educación secundadaria por la VIU, Universidad Internacional de Valencia. Ha trabajado como profesora asociada en la Universidad Carlos III de Madrid durante dos cursos, aunque su vida laboral se centra mayoritariamente en los medios de comunicación. Como periodista en los informativos de Canal 9, informativos Telecinco, Noticias Cuatro y actualmente como presentadora de los informativos de À Punt Mèdia, la televisión pública valenciana. Universidad de Valladolid, España

marta.ventura@alumnos.uva.es ORCID: 0000-0002-0326-3338

Salomé Berrocal Gonzalo. Profesora Titular de Periodismo (2007), catedrática acreditada (2016), en la Universidad de Valladolid, especialista en Comunicación Política, desde la obtención de su grado de Doctora en 1996 con una tesis centrada en esta área de estudio. Desde entonces, ha publicado más de 50 trabajos de investigación, 6 de ellos son monografías completas. Ha participado en 9 proyectos de investigación financiados en convocatorias públicas nacionales e internacionales, en 3 de ellos como Investigadora Principal. Ha realizado numerosas estancias de investigación, 4 de ellas corresponden a movilidades en régimen competitivo. Cabe destacar las desarrolladas en instituciones de prestigio como la George Washington University, University of California San Diego, Suffolk University, en Estados Unidos, University of Toronto en Canadá o las universidades de Milán o de la Sapienza, en Italia, entre otras. Cuenta con cuatro quinquenios docentes y tres sexenios de investigación. Universidad de Valladolid, España salomeb@hmca.uva.es

ORCID: 0000-0002-0483-0509

Cómo citar este artículo:

Redondo García, M.; Ventura Meneu, M. y Berrocal Gonzalo, S. (2020). Nuevos roles del líder político en programas televisivos de infoentretenimiento. Doxa Comunicación, 30, pp. 37-53.

https://doi.org/10.31921/doxacom.n30a2 
Recibido: 15/10/2019 - Aceptado: 08/02/2020

\section{Resumen:}

La función tradicional del político en los medios de comunicación ha sido la de fuente informativa sobre la actualidad política. La irrupción del infoentretenimiento político (politainment) en televisión en los años 90 abrió el espectro de roles desempeñados por los líderes que empezaron a aparecer en formatos no estrictamente informativos y en facetas inéditas, hablando sobre su vida personal o como comentaristas de la actualidad. Esta asunción de nuevos cometidos ha evolucionado favorecida por la hibridación de géneros. La investigación aborda los nuevos perfiles asumidos por los políticos en los programas de politainment que hasta el momento no habían sido catalogados. El artículo aporta una conceptualización de estos nuevos papeles y un estudio empírico sobre los roles de los políticos aparecidos en Las Mañanas de Cuatro como magacín matinal representativo del infoentretenimiento televisivo (Sánchez-García y Campos Zabala, 2017). Entre las conclusiones destacan su presencia significativa y el desempeño de funciones novedosas tales como las de político-cronista, político-contertulio o político-celebrity.

Palabras clave:

Comunicación política; televisión; infoentretenimiento; politainment; análisis de contenido.
Received: 15/10/2019 - Accepted: 08/02/2020

\section{Abstract:}

The traditional role of the politician in the mass media is to be the source of information of political news. The outbreak of political infotainment in television (politainment) during the 90's opened a broader range of roles for political leaders as they began to appear in new formats that were not always purely informative, but also included details about their private lives, acting as presenters or even as celebrities. The present research studies the new profiles of politicians in TV. The paper suggests a conceptualization of these roles which is completed by an empirical study about the roles of the politicians that appear in the TV programme Las Mañanas de Cuatro chosen as a significant TV infotainment programme (Sánchez-García y Campos Zabala, 2017). Among the conclusions, it is relevant to highlight the emergence of the main characters in this format and the roles they assume such as political chroniclers, political debaters or political celebrities.

Keywords:

Political communication; television; infotainment; politainment; content analysis.

\section{Introducción}

La función tradicional del político en relación a los medios de comunicación ha sido la de fuente informativa sobre la actualidad política, facilitando los datos que la prensa necesita para suministrar noticias (De Fontcuberta, 1993). Bien es cierto que se trata de un proveedor peculiar de información que ocupa una posición preferente en la jerarquía mediática, formando parte de la nómina de "fuentes estables" (Armentia y Caminos, 1998), "proactivas" e incluso "compulsivas" (Borrat, 1989) puesto que asumen la iniciativa de la comunicación y cuentan con recursos estratégicos para trasladar al público su visión de la realidad (Borrat, 1989). Son lo que Rodrigo Alsina denomina "fuentes de rutina" que representan una referencia dominante ante una amplia gama de acontecimientos, adquiriendo un "derecho de acceso semiautomático a los medios de comunicación" (1999: 125).

Desde esa posición, el político intenta estar presente en los medios con el fin de fraguarse una imagen pública y llegar al electorado. Los partidos buscan acaparar espacio informativo logrando "mayor número de noticias sobre temas propios o conseguir dominar la estructura de fuentes informativas con actores de la organización política en cuestión” (Casero, 2009: 356). Una vez conseguida esa presencia, aspiran a controlar el discurso mediático en cuanto a la jerarquía noticiosa, la interpretación de los hechos o los argumentos dominantes: "los sujetos políticos ansían aprovecharse, así, de una 
construcción mediática de la realidad política favorable, que les permita beneficiarse de diversos réditos en el terreno simbólico" (Casero, 2009: 357).

Para lograr ese objetivo, la política ha seguido un proceso de "mediatización” (Mazzoleni y Schutz, 1999; Kepplinger, 2002; Casero, 2009; Habler, Maurer y Oschatz, 2014; Strömbäck y Esser, 2015) que describe cómo los valores imperantes en los medios y privilegiados por estos son asimilados por determinadas fuentes que se adaptan al mensaje mediático en una simbiosis de procedimientos (Redondo, 2011). Ya Krinppendorff, en 1990, detectó cómo "las propiedades de un medio en cuanto al registro y difusión de la información ejercen un profundo efecto sobre la naturaleza de las instituciones que pueden sustentarse mediante las comunicaciones a través de ese medio" (1990: 67).

La mediatización política definiría el proceso por el que el actor político asume la lógica comunicativa periodística, adaptándose a las necesidades de los medios (Kepplinger, 2002). Una aspiración que se hace fundamental en el caso de la televisión, dada su capacidad para popularizar personas e ideas.

Esa adecuación a la lógica mediática incluye estrategias como: la personalización de la acción política, la simplificación del mensaje, la creación de lemas y eslóganes que sirvan como totales televisivos o cortes radiofónicos, la construcción artificial de hechos noticiosos o la búsqueda de photo opportunities.

Al ser un fenómeno adaptativo, la mediatización no es estable, sino que ha evolucionado según se ha ido modificando la lógica mediática. Y esta ha vivido en los últimos años un cambio de paradigma.

\subsection{La lógica mediática del politainment}

La lógica mediática y, de forma más acusada, la lógica televisiva ha experimentado un cambio profundo desde los años 90 del siglo pasado en una apuesta por el espectáculo como forma de ganar audiencia en un entorno altamente competitivo: "la necesidad de hacer entretenimiento se ha vuelto una prioridad crucial para los programadores de televisión que se han visto forzados a adaptar las características de los formatos de entretenimiento y los modos de la conversación que privilegian un estilo comunicativo informal, con énfasis en la personalización, el estilo, las herramientas del storytelling y el espectáculo" (Thusu, 2007: 3).

Este proceso de variación en la naturaleza de la información ha afectado también a la política llegando a acuñarse el término politainment para denominar el tratamiento "frívolo, superficial o espectacular" de la información política (Berrocal, 2017).

En este contexto, se observan ciertos cambios en el proceso de ajuste de los actores políticos a la lógica televisiva, incorporando nuevos atributos y tácticas a los ya consolidados, con el fin de ganar y mantener el protagonismo mediático. La Tabla 1 recoge gráficamente este inventario de atributos (antiguos y nuevos) en los que confluyen la lógica televisiva y la lógica política. 
Tabla 1. Atributos (A) del actor político según la lógica política y la lógica televisiva

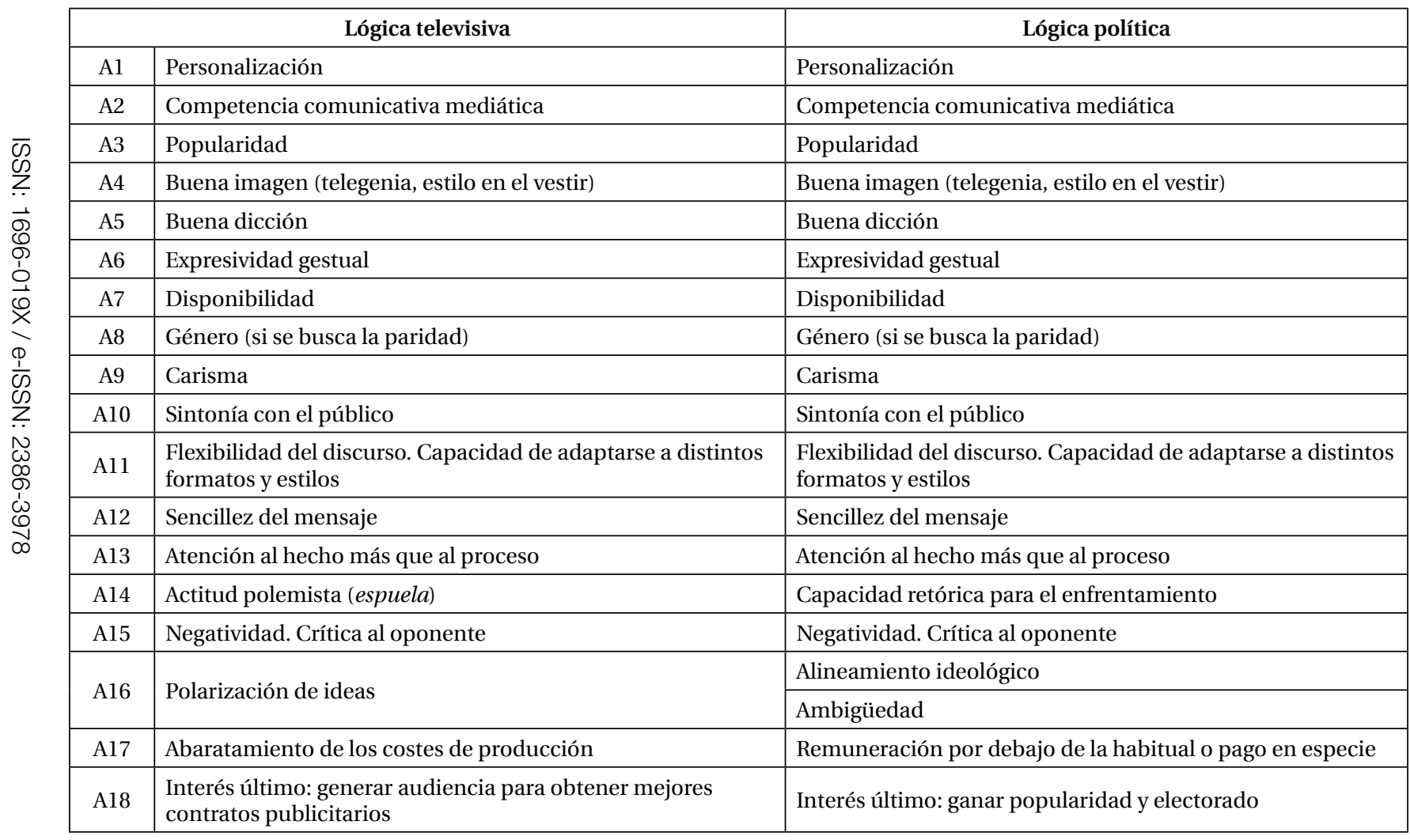

Fuente: elaboración propia

La personalización (A1) es una exigencia para la televisión que necesita poner rostro y voz a las ideas para que sean transmisibles. Influida por esa necesidad, la política vive un proceso paralelo con un protagonismo creciente de los líderes frente a las doctrinas, conceptos u organizaciones colectivas (Rebolledo, 2017) y, derivado de ello, una preocupación del candidato por construirse y mantener un perfil de cara a su electorado.

Muchas de las cualidades buscadas en el político mediático tienen que ver con esa personalización, entre ellas poseer una buena imagen (telegenia) (A4), una voz clara y agradable (A5), expresividad gestual (A6), carisma entendido como el don para atraer al espectador a través de la presencia y la palabra (A9) y, por supuesto, la popularidad que garantiza ser reconocible por el público (A3). Otra característica ineludible en el político televisivo es tener competencia comunicativa mediática, es decir, conocer el funcionamiento del medio y los códigos que rigen en él para utilizarlos en provecho propio 
(A2). Junto a ello, existen requerimientos que se derivan de las exigencias productivas, tales como la disponibilidad horaria para intervenir cuando sea requerido (A7) o el género cuando el espacio busca la paridad representativa (A8).

Pero, además, surgen nuevas demandas fruto de la expansión del politainment. En las tertulias, debates o programas de entrevistas, la nueva lógica mediática privilegia la confrontación, "futbolizando" el diálogo televisivo (Sánchez-García y Campos Zabala, 2017). De esta forma, se ha incorporado una nueva clave de acceso de los productores de información a la televisión que radica en su capacidad para generar una polémica que eleve el índice de audiencia. De hecho, muchos de los invitados a programas talk show son "polemistas profesionales" (Mercado, 2002) (la jerga televisiva los apoda espuelas), expertos en encontrar los aspectos más sensacionalistas de la realidad y realizar las observaciones más extremas.

Se exige que el político tenga capacidad de polemizar sobre una variedad de asuntos y no rehúya el enfrentamiento (A14). Bien es cierto que, en este punto, los intereses del medio y del partido pueden entrar en conflicto. La lógica de la formación es de inferir que privilegie para su representación mediática a aquellos políticos que estén más altos en su escalafón, al resultar más fiables por su sintonía ideológica con la oficialidad del partido. Sin embargo, el medio puede preferir al político discordante por su capacidad para crear polémica, no solo con los adversarios políticos, sino incluso con sus mismos correligionarios, ofreciendo un punto de vista más personal y original. En cualquier caso, se buscará al político irónico en la crítica al antagonista dado que el mensaje televisivo privilegia la negatividad y el ataque (A15), más que la propuesta constructiva y su explicación (Habler et al., 2014).

En aras al populismo, se pide que el político apele al público, sea capaz de erigirse en su portavoz y adule sus planteamientos (A10). También se impone que el mensaje político sea fácilmente comprensible para poder llegar a la audiencia televisiva, esencialmente heterogénea (A12). Dada la inmediatez y fugacidad del medio, "la claridad expositiva en el discurso ha de ser una máxima. Esta claridad afecta al lenguaje, y en televisión deberá ser claro, breve, conciso y preciso" (Salgado Losada, 2005). En ese mismo sentido discurre la necesidad impuesta por los medios de atender más a los hechos puntuales que a los procesos que, inevitablemente, exigen una explicación y contextualización mayores (Habler et al., 2014) (A13). Buscando esa sencillez, se impone la ausencia de ambigüedad (A16): los medios prefieren los mensajes polarizados, tal como aprecian Sánchez-García y Campos Zabala en su análisis de la tertulia política televisiva: "el tertuliano periodista y el contertulio político salen al escenario con posturas `preconcebidas’ y reconocibles por el espectador (...) esto explica el 'enganche` de este tipo de tertulia con la audiencia que busca refrendar sus posturas ideológicas al adherirse a contertulios ideológicamente muy definidos" (2017: 83). Sin embargo, el político optará, en ocasiones, por un mensaje ambiguo frente al concreto que a la postre pueda evidenciar incoherencias (Habler et al., 2014).

Dado que los programas de infoentretenimiento amalgaman una enorme variedad de formatos, se busca que el político sea flexible a la hora de adoptar distintos estilos discursivos (A11), así, puede aparecer en su faceta institucional en los noticiarios cuando hace referencia a la actualidad desde los planteamientos de su formación o asumir una faceta individual en un talk show aportando sus impresiones personales o narrando sus vivencias en relación a asuntos no relacionados con la política. 
Igualmente, en cuestiones de tipo retributivo coinciden la lógica política y la mediática, aunque por motivos distintos (A17). Dado que el político está interesado en aparecer en los medios acepta unos emolumentos bajos o recibe su pago en especie (la popularidad que el espacio le proporciona), contribuyendo a abaratar los costes de producción.

El objetivo último de esta simbiosis buscada por medios y políticos se aprecia distinto, aunque, de nuevo, convergente (A18). El medio persigue despertar el interés de los espectadores para elevar los índices de audiencia; el político busca acaparar esa misma atención de la audiencia, pero concebida como electorado potencial.

\subsection{Ampliación de los roles desempeñados por los actores políticos en el politainment televisivo}

Junto al movimiento de adaptación a la lógica mediática, se ha producido una asunción de nuevos roles de los líderes políticos en los espacios televisivos. Este proceso ha estado favorecido por la hibridación de géneros, de modo que muchos formatos han evolucionado permitiendo la entrada del político en el proceso productivo de la información y la opinión, acaparando protagonismo e incluso supliendo la labor del periodista como comentarista o cronista de la actualidad. Este fenómeno se produce, además, en un contexto favorable, dado que la función del informador se ha vuelto menos exclusiva, más difusa y a menudo desempeñada por otros "actores para-periodísticos" (Loeb, 2017). También porque el político, dada la fragmentación de las audiencias, tiene que estar presente en programas de muy diverso corte para asegurarse el contacto con su electorado (Diamond, McKay y Silverman, 1993).

La irrupción del politainment en televisión abrió el espectro de funciones ejercidas por los líderes políticos que comenzaron a aparecer en formatos no estrictamente informativos y en facetas inéditas, hablando sobre su vida personal, sus gustos y emociones, como comentaristas de una variedad de temas, como celebrities del mundo del espectáculo e incluso como actores en series y películas (Berrocal, 2016).

La presente investigación considera necesario en este punto delimitar esos nuevos roles asumidos por los políticos en los programas televisivos que hasta el momento no habían sido catalogados. Aquí se aporta una propuesta de conceptualización que puede estar sometida a ampliación en trabajos posteriores dado el carácter cambiante del fenómeno.

Político-fuente. Como vértice del sistema informativo, las fuentes políticas están presentes de forma constante en los medios de comunicación hasta el punto de "condicionar" la producción informativa (Cesareo, 1986). De hecho, suministran una buena parte de las noticias que formarán parte de la agenda mediática.

El político como fuente asume un rol institucional en su calidad de representante de la organización de la que forma parte.

Político-contertulio (eventual o estable). La tertulia política, bien como género puro, bien formando parte de un programa contenedor, está muy presente en la parrilla televisiva española desde la década de los 90, importada desde el medio radiofónico. En la nómina de tertulianos, la figura del político es una constante. Sánchez-Serrano (2005) constata cómo a finales de 1996, 34 diputados tenían autorización de la Cámara para participar en tertulias radiofónicas. Abejón (2013) actualiza el dato en 2013 confirmando que 123 diputados participaban entonces en los debates de los medios. 
En buena medida, las tertulias actuales asumen el tono propio de la polarización y la polémica "con la organización de los intervinientes en bandos que expresan juicios categóricos (cerrados y explícitos) a los que se adhiere la audiencia, como parte del espectáculo" (Sánchez-García y Campos, 2017: 86). Algunos ejemplos son las tertulias de programas tales como La Sexta Noche, El gato al agua, La Noria o los magazines matutinos de las distintas cadenas.

Político-entrevistado. Dentro del macroformato del talk show, es una constante la entrevista al político que da cuenta de su gestión y comenta la actualidad. En este género el entrevistador es quien marca el tono y el desarrollo del encuentro. Así, cuando se ciñe a un formato de fiscalización del poder (watch dog), resulta incisivo, plantea preguntas delicadas e incluso molestas evitando caer en un seguidismo propagandista (Halperin, 1995). Sin embargo, cada vez resulta más frecuente encontrar en la parrilla entrevistas blandas o "soft interviews" (Berrocal y Quevedo, 2014) donde la vida privada del político adquiere protagonismo y aparecen expuestos sus valores y sentimientos con el fin de humanizar al líder (Quevedo, 2017). En este tipo de formatos son abundantes las "preguntas referentes a la personalidad, gustos y aficiones del personaje, y en menor medida, a su situación sentimental y a la conciliación de la vida laboral y familiar” (Quevedo, 2017: 132). Es el caso de programas como En la tuya o en la mía, Planeta Calleja o Viajando con Chester.

Político-cronista. El político narra con estilo periodístico un hecho noticioso que ha vivido o presenciado en primera persona y al que ha asistido en su condición de miembro de su formación. Habla directamente a la cámara, mirando al espectador, e incluso llega a portar en su mano el micrófono de la cadena. En este caso, el discurso institucional dominante se disfraza de estilo periodístico, hurtando al informador la función de intermediación.

Político-disertador. El político se dirige a la ciudadanía mediante una alocución pública difundida habitualmente en directo. Esta función es infrecuente en el panorama español. Son ejemplo de ello las intervenciones del líder político cuando apela a los espectadores sin la mediación del periodista, normalmente en casos extraordinarios: mensajes a la nación tras graves atentados terroristas o mensajes de Nochebuena del Rey y de distintos presidentes autonómicos. Este tipo de intervenciones sintoniza con el concepto de "Going Public" de Kernell (1997) donde el político sortea "los filtros propios de la mediación institucional del sistema mediático" (Casero, 2009: 361) para lanzar su discurso sin el proceso de selección e interpretación del periodista.

En estos casos el mensaje es puramente institucional y todos los elementos que lo componen: el texto de la alocución, el tono, la gestualidad, la puesta en escena, han sido cuidadosamente diseñados para lograr el objetivo previamente determinado: obtener legitimidad, ganar adeptos o tranquilizar en tiempos de crisis (Gaspar y Ibeas, 2015).

Político-presentador. Otro tipo de espacios sin intermediación periodística son aquellos en los que el político presenta o coordina un programa a través del que se dirige libremente a la ciudadanía. El caso internacional más llamativo es el del ex presidente Hugo Chávez con su Aló Presidente que se emitió semanalmente en el canal público venezolano durante más de una década. En este tipo de formato, el político expone y anuncia sus iniciativas, a menudo en un tono propagandístico y, eventualmente, responde a las preguntas formuladas por los ciudadanos. En este sentido, la intervención del político comparte características del rol político-disertador.

En el panorama español solo encontramos el caso del líder de Podemos, Pablo Iglesias, que dirige y presenta dos programas televisivos asumiendo completamente las funciones de periodista: el espacio de entrevistas Otra Vuelta de Tuerka 
(Publico.tv) y Fort Apache, una tertulia política emitida en HispanTV, un medio alternativo patrocinado por el gobierno iraní que emite para la comunidad hispanohablante (Cembrero, 2012).

Político-paródico. En programas de humor y sátira política, específicamente en los informativos paródicos, el líder sirve de inspiración para generar una caricatura de la actualidad. En Las noticias del guiñol, los políticos eran representados por monigotes de látex que protagonizan escenas absurdas (Berrocal, Abad, Cebrián y Pedreira, 2003). Los reportajes provocadores de Caiga quien Caiga sometían al político a situaciones incómodas buscando ridiculizarle y evidenciar sus defectos. En La noche de José Mota, el humorista se disfrazaba de líderes políticos en sus sketches para criticar la realidad sociopolítica. En los vídeos manipulados de El Intermedio, las imágenes y declaraciones del político son editadas para generar situaciones y mensajes ridículos.

En este caso el político carece de capacidad para controlar el mensaje, a pesar de ser el protagonista de la acción.

Político-celebrity. El político asume la notoriedad de una celebrity y aparece representado mediáticamente por el interés que suscita como personaje famoso, por su personalidad y su vida privada, y no por su actividad política. Para Street (2004), la aparición y desarrollo de la figura del político-celebrity viene favorecida por el proceso de mediatización, la personalización política y el ascenso de "un populismo desesperado, en el que la presentación y la apariencia sustituyen a la política y a los principios" (2004: 436). Para Rebolledo, es la sobreexposición mediática de los políticos lo que provoca que adquieran ese "estatus de celebridades" (2017: 167) que les equiparan con estrellas del mundo del espectáculo.

Político-showman. El político en este rol realiza una actividad propia del mundo del espectáculo: canta, baila, toca algún instrumento, como si de una actuación profesional se tratase. Este rol es efecto de la espectacularización política en la que es preciso que el líder exhiba otras virtudes que sus propuestas o su capacidad de gestión de lo público para sintonizar con su electorado. Normalmente el político asume ese papel en espacios de info-show en los que el presentador le solicita que realice esa actividad.

Político-actor. El político interviene realizando cameos en series de televisión o películas, en su calidad de celebrity. Son conocidos los cameos de Mariano Rajoy en la serie Jacinto Durante representante de TVE o los de Alfonso Guerra, Javier Arenas o Carod Rovira en 7 Vidas (Telecinco).

\section{Metodología}

El objetivo principal de este estudio es examinar los nuevos roles asumidos por los políticos en programas de politainment, concretamente se analiza Las Mañanas de Cuatro, emisión catalogada dentro de la propia cadena Cuatro como un magacín de actualidad en directo. Este programa ha sido considerado, junto a Al rojo vivo y La sexta noche, como uno de los programas españoles de tertulia política que mejor representa el fenómeno de la política espectacularizada en la programación televisiva (Sánchez-García y Campos, 2017).

La investigación incluye, además, tres objetivos secundarios: 1) examinar cómo se reparte el tiempo entre políticos y periodistas en Las Mañanas de Cuatro, con el afán de conocer a quién se le otorga mayor protagonismo; 2) conocer los partidos políticos y medios de comunicación más representados, con el objeto de averiguar qué formaciones políticas y 
medios están participando en esta modalidad de tertulia y 3) establecer los perfiles de periodistas y políticos atendiendo a categorías básicas como edad y género, con el ánimo de saber cuál es el prototipo de informador o de político asistente a este formato.

La hipótesis de partida contempla que el estilo narrativo del politainment ha proporcionado nuevas actividades comunicativas para los líderes generándose nuevos roles del actor político que atiende a figuras como las del político-contertulio, político-celebrity o político-cronista.

Las Mañanas de Cuatro nació en 2006 vinculado a la compañía Plural Entertainment y presentado por la periodista Concha García Campoy. Desde marzo de 2015 hasta el fin de sus emisiones en junio de 2018, el encargado de conducir el espacio fue Javier Ruiz. El programa transcurría de lunes a viernes en la franja matinal, entre las 11,20h. y las 14,15h. En el equipo trabajaron 40 personas entre dirección, producción, realización y redacción.

La muestra analizada es de 1.050 minutos (17 horas y 30 minutos), correspondientes al examen de 7 programas de Las Mañanas de Cuatro, seleccionados de manera aleatoria en el mes de febrero de 2018. Por sorteo, el día en el que se inicia la recopilación de la muestra es el 8 de febrero y a partir de ahí se extiende durante una semana, hasta el 16 de febrero. El share promedio de los programas analizados es del $7,7 \%$.

La estructura del programa gira en torno a una mesa de debate moderada por el presentador. Los integrantes de la mesa son mayoritariamente periodistas, aunque también se incorporan políticos, expertos en comunicación política, economistas, así como invitados relacionados con los temas de actualidad.

Además del debate que se genera en la mesa de tertulianos, el programa se nutre de:

1-. Dúplex. Conexiones en directo con personajes de actualidad que, sin necesidad de estar acompañados por un periodista, entablan conversación con el presentador o se suman al debate abierto en la mesa del plató.

2-. Conexiones en directo con reporteros. A las tradicionales conexiones en directo con reporteros en la calle, se añaden puntos fijos de conexión: el Congreso de los Diputados, la Audiencia Nacional y la Redacción del programa, desde dónde se narran las noticias de última hora.

3-. Vídeos, reportajes, totales, colas y señales en directo. El presentador da paso a los vídeos elaborados por los redactores del programa, declaraciones e imágenes que surgen a lo largo de la mañana y también a los directos que se van produciendo según la actualidad informativa.

De la muestra total acumulada, esta investigación selecciona para su análisis 721 minutos que es el tiempo que el programa destina a la intervención de políticos, periodistas, reporteros y expertos. El resto, 329 minutos, no se incluyen en el análisis, al corresponder a entradillas del presentador, vídeo/reportajes locutados por redactores y publicidad. La estadística descriptiva (Berger, 2015; Daymon y Holloway, 2011) indica que la muestra posee representatividad mediática, permite organizar los datos de manera sencilla y los resultados generados pueden utilizarse como patrón en futuros modelos predictivos con análisis de tipo inferencial y muestras más grandes.

El estudio descriptivo realizado utiliza un método de análisis de contenido de tipo cuantitativo para medir: distribución de tiempo entre periodistas y políticos; modalidad de las intervenciones; representación de medios de comunicación y 
partidos políticos, edad y género de los periodistas y políticos participantes, y un análisis cualitativo para establecer los roles de los políticos. Para la recogida de información se han empleado plantillas de análisis estructuradas en 25 variables organizadas según los siguientes parámetros:

a) Mesa de análisis: número de participantes; duración y modalidad de sus intervenciones; medios de comunicación y partidos políticos representados; prototipo periodista y político interviniente (edad, sexo, formación).

b) Perfil de los políticos: político-fuente; político-contertulio; político-entrevistado; político-cronista; político-disertador; político-presentador; político-paródico; político-celebrity; político-showman; político-actor.

La codificación ha sido realizada por dos investigadoras sobre la muestra total de 721 minutos, con el afán de asegurar la fiabilidad del estudio.

\section{Resultados}

Uno de los objetivos fijados en esta investigación es la medición del tiempo dedicado a los políticos en el programa. En el Gráfico 1 se observa que el 78,77\% del tiempo examinado (568 minutos) se dedica a la intervención de periodistas y expertos; el tiempo ocupado por los políticos es del 21,22\% (153 minutos). Por tanto, el tiempo dedicado a los periodistas (en plató y reporteros) y expertos es tres veces superior al destinado a las intervenciones de los políticos, convirtiéndose así en los protagonistas del programa. Esta situación no debe empañar el reconocimiento del papel que adquieren los políticos al incorporarse de manera activa a este tipo de formatos.

\section{Gráfico 1. Distribución por tiempo}

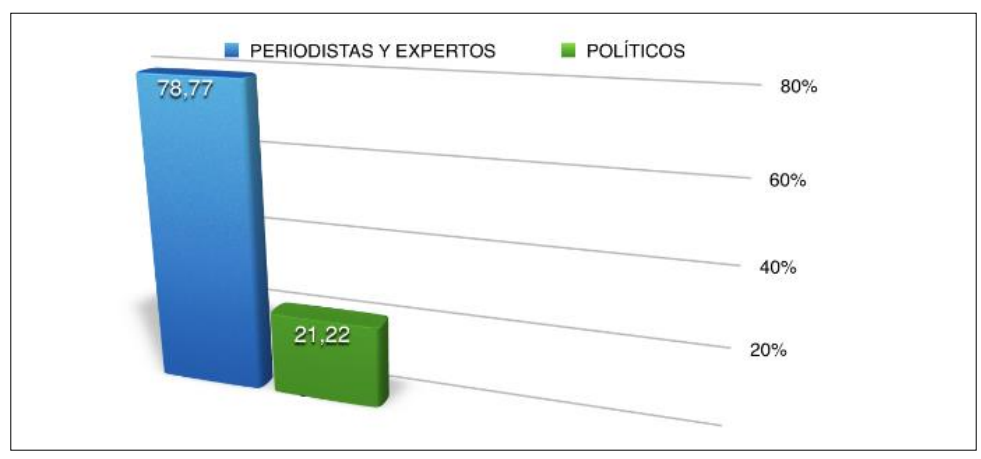

Fuente: elaboración propia

Sobre el lugar desde el que se producen las intervenciones de los políticos en el programa, estas se realizan habitualmente fuera del plató, el $71 \%$ de las apariciones. Un dato que indica que los actuales actores políticos tienen que estar preparados para dar respuesta inmediata a la actualidad del día y hacerlo desde un entorno que, en la mayoría de las ocasiones, no es el del plató televisivo. Una circunstancia que se relaciona con el atributo relativo a la disponibilidad del político para intervenir al ser requerido (A7) (Véase Tabla 1). 
Esta modalidad predominante de la intervención en exteriores de los políticos se complementa con el tiempo que ocupan los reporteros, a través de sus conexiones en diferentes puntos donde ocurre la noticia. Los minutos destinados a reporteros y políticos fuera de plató son prácticamente los mismos, 117 minutos frente a 108.

Sin embargo, como ya se ha señalado, la presencia en el plató de los políticos es mucho menor que la de los periodistas y expertos: solo 15 minutos frente a 451 minutos. A la hora de comentar la actualidad el peso del programa en el plató recae sobre profesionales de la información y en menor medida en expertos: 36 son profesionales del periodismo (el $67,9 \%$ de la muestra), 12 expertos (22,6\%) en diferentes materias: economía, derecho, comunicación, capaces de analizar cualquier noticia que surja durante la emisión. El número de políticos en su función de tertulianos en plató es de 5 (9,4\%).

De esta manera Las Mañanas de Cuatro mantiene una mesa de análisis continuamente activa que se puede utilizar, por ejemplo, en tiempos muertos a la espera de una rueda de prensa en directo o bien en últimas horas que acaban de conocerse y de las que no se tiene mucha información.

La mesa de tertulianos constituye el músculo de análisis que permite al programa estar vivo, informativamente hablando, durante las dos horas y media de directo. Así, el plató se constituye como el espacio dominado por los informadores profesionales, feudo de su labor especializada, aunque un análisis diacrónico puede alumbrar un retroceso en su protagonismo en favor de otros actores "para-periodísticos" (Loeb, 2017) con especial relevancia de los políticos.

Respecto a los 36 profesionales del periodismo que aparecen en la muestra, los medios más representados son la Cadena Ser y eldiario.es (11,11\%), seguidos del digital Público y el diario ARA de Cataluña (8,33\%).

Como evidencia el Gráfico 2, hay una alta presencia de medios digitales frente a medios de comunicación tradicionales como la prensa de referencia (El País, El Mundo, $A B C$, entre otros) que carece de representación en la muestra.

Gráfico 2. Medios de comunicación representados

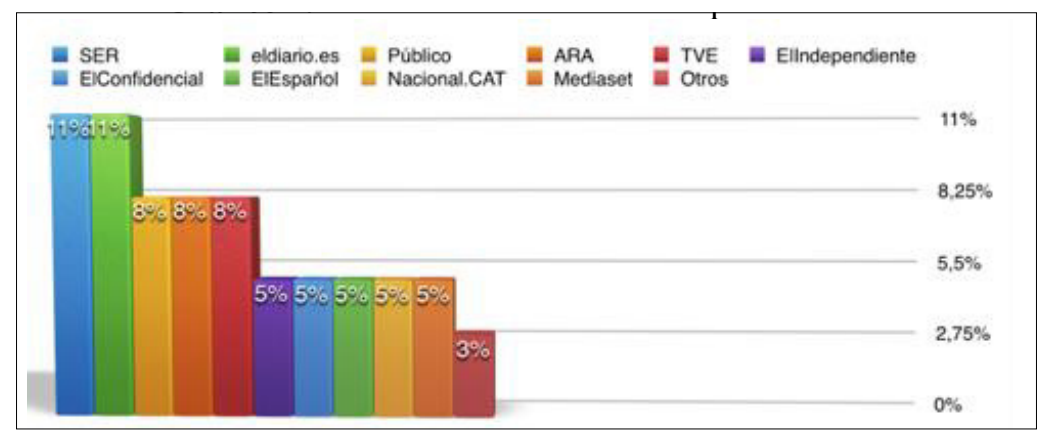

Fuente: elaboración propia

En el apartado de distribución de los distintos partidos políticos según el tiempo dedicado en el programa (Gráfico 3), se observa que Ciudadanos es la formación con mayor peso, ocupa un 25\% (33 minutos). Le sigue el Partido Popular y Podemos con el 18\% (24 minutos). Izquierda Unida y Compromís obtienen 11 y 12 minutos respectivamente (11\% y 9\%). El 
partido con menos representación es el Partido Socialista, con 3 minutos (2\%). Este escaso celo en el reparto de tiempos dedicados a cada formación, que no resulta equitativo respecto a su representación parlamentaria, indicaría que se priman otros valores sobre los que marca la legitimidad democrática, como la competencia comunicativa mediática (A2), la popularidad (A3), el carisma de sus portavoces (A9) o la capacidad para generar polémica (A14) (Véase Tabla 1).

Gráfico 3. Partidos políticos representados

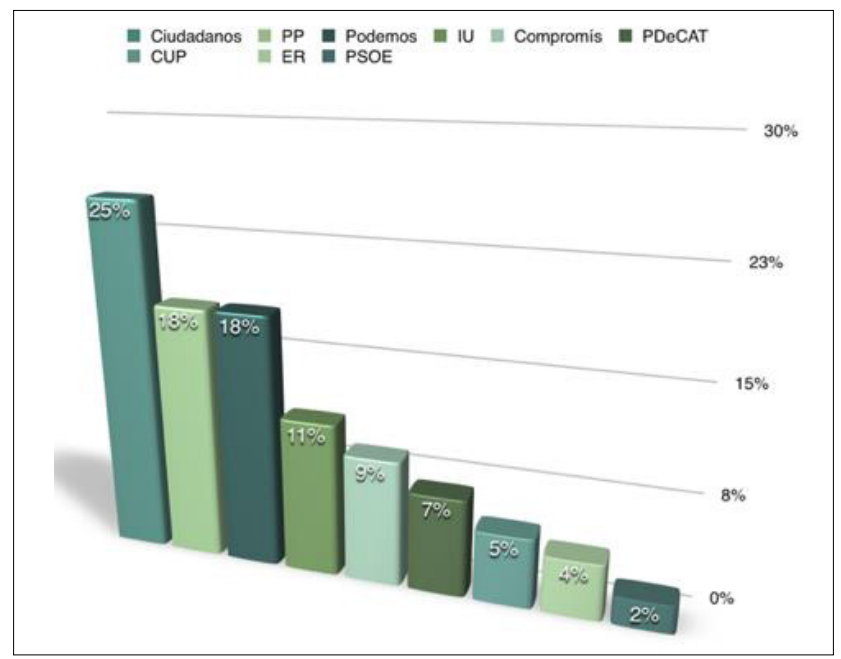

Fuente: elaboración propia

En lo que respecta al género de los intervinientes se aprecia una discriminación de la mujer, tanto en los cargos políticos como en los procedentes de los medios de comunicación y expertos, con índices de sobrerrepresentación masculina casi idénticos (en torno al $64,5 \%$ de hombres frente al $35,5 \%$ de mujeres).

Gráfico 4. Género de políticos y periodistas y expertos

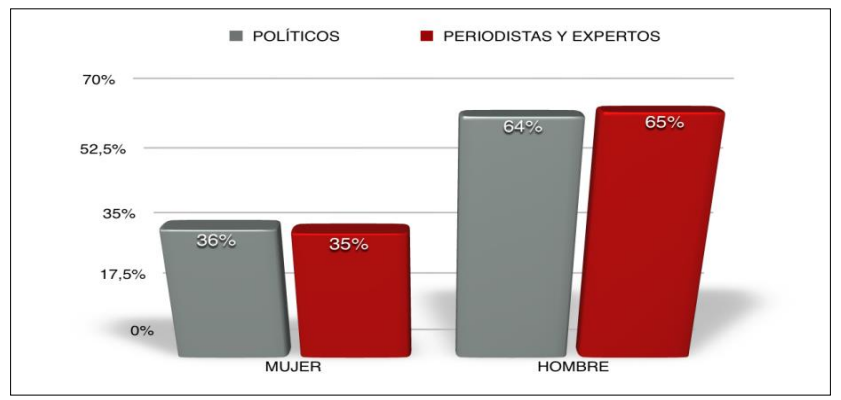

Fuente: elaboración propia 
En cuanto a la edad, la franja predominante entre los políticos es de entre 30 y 39 años (33,3\%), seguida de cerca por la franja de los 50 a 59 años que acumula el $28,6 \%$ del total. El rango de edad mayoritario de los tertulianos periodistas es más elevado, oscila entre los 50 y 59 años (29,17\%). Le sigue la franja de edad inmediatamente anterior, entre 40 y 49 años, que representa el 22,92\% del total. Una edad media más joven de los políticos se podría relacionar con los atributos de telegenia y buena imagen (A4) (véase Tabla 1) buscados por los partidos a la hora de elegir a sus representantes ante los medios.

Gráfico 5. Edad de políticos y periodistas

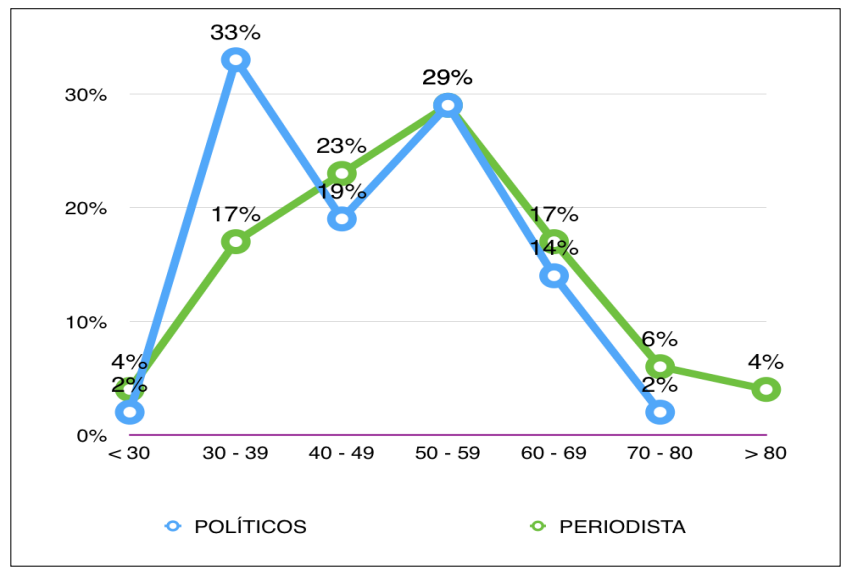

Fuente: elaboración propia

Los líderes políticos adoptan cinco perfiles o roles diferentes cuando intervienen en Las Mañanas de Cuatro. El político-fuente representa el papel más clásico del político, aquel que aparece en el programa para explicar la postura del partido sobre un asunto del que generalmente es protagonista. Este rol es el más repetido en el programa, acapara el $51 \%$ de las intervenciones de políticos. El segundo perfil más repetido es el del político-contertulio, es decir, el representante público que se adapta al medio televisivo y se transforma en analista, se pone a disposición del presentador para que este le pregunte sobre cualquier tema de actualidad y debate con otros tertulianos. El político-contertulio ocupa el $42 \%$ de las intervenciones de la muestra. El tercer rol con mayor presencia es el político-celebrity, el político elevado a la categoría de hecho noticiable cuya personalidad o vida privada adquiere interés para el público, el $4 \%$ de las intervenciones corresponden a este rol. El político-cronista, el que asume las funciones del periodista en el programa (aportar y cuestionar información) supone un $2 \%$ de la muestra. 


\section{Gráfico 6. Perfil de los políticos}

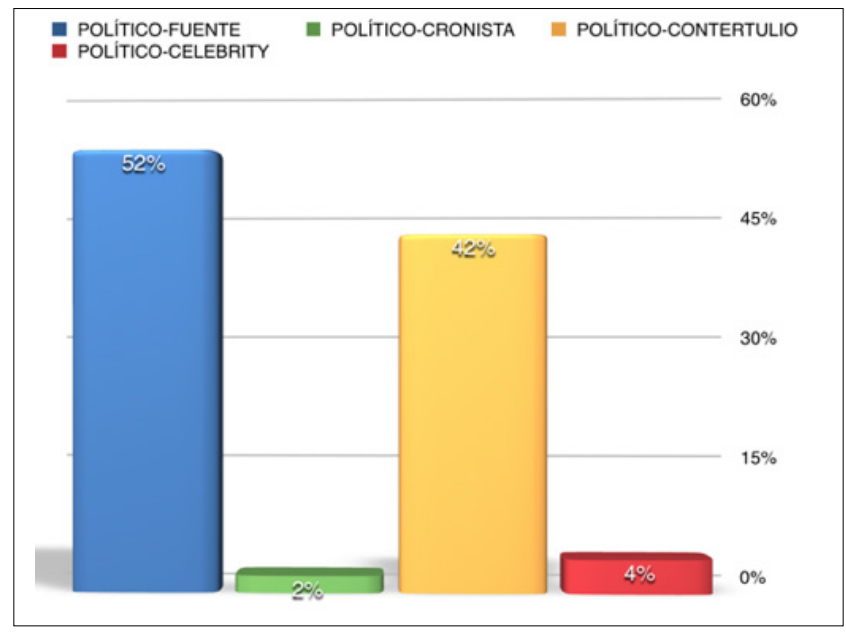

Fuente: elaboración propia

\section{Discusión y conclusiones}

El análisis descriptivo que se ha llevado a cabo sobre el programa Las Mañanas de Cuatro indica cuestiones de interés en el desarrollo de los programas de tertulia política, que se enmarcan en el politainment, así como en los roles que adquiere el líder político.

Las tertulias televisivas que en su formato clásico se entendían como un espacio para la confrontación entre periodistas acerca de temáticas vinculadas a la actualidad han evolucionado transformándose en tertulias monotemáticas en las que prácticamente solo existe la política.

Si a finales del siglo XX el modelo predominante de tertulia era la conversación entre tertulianos-periodistas, en el siglo XXI la tertulia adopta un formato híbrido como es el caso de Las Mañanas de Cuatro, en el que la mesa de análisis se acompaña de intervenciones en directo, realizadas desde el exterior del plató, de políticos, reporteros y expertos. A ello se añade el uso de vídeos, reportajes o totales que aderezan la emisión y le otorgan un carácter espectacular al dotarla de dinamismo y teatralización.

El trabajo de campo evidencia la presencia protagonista en Las Mañanas de Cuatro de tertulianos, denominación que incluye a periodistas y expertos, además de líderes políticos y reporteros. Destaca que el porcentaje de tiempo destinado a las intervenciones de políticos en directo es de un $21 \%$. Por tanto, un tercio del tiempo del programa se destina a las participaciones de los líderes políticos y mayoritariamente estas se realizan en directo, fuera del plató de televisión y de manera exclusiva para dicho programa o recogiendo comparecencias públicas. Esta situación provoca que, en la mayoría 
de las ocasiones, el político tenga que adaptarse a las necesidades informativas de los medios, dejando a un lado un discurso trabajado y encorsetado, ante la urgencia mediática de responder a preguntas en directo sobre la actualidad.

Una situación llamativa la constituye el hecho de que sean los nuevos partidos políticos, Ciudadanos y Podemos, los que cuenten con mayor dedicación en el desarrollo del programa, junto al partido del Gobierno (en la fecha de recogida de la muestra, el Partido Popular). La necesidad de ganar visibilidad ante el electorado podría explicar esa profusión, así como su aceptación a asumir nuevos papeles en su relación a los medios de comunicación.

El perfil de los intervinientes es mayoritariamente masculino tanto en el caso de los periodistas y expertos como en el de los políticos. Pero, mientras que los políticos que tienen presencia en este programa se encuentran entre los 33 y 39 años, en el caso de los periodistas y expertos la franja de edad dominante corresponde a la de los 50 a 59 años. Parece que la experiencia pesa entre los informadores, mientras que los partidos deciden enviar a políticos jóvenes a este tipo de espacios. En cuanto al rol de los políticos, se observa que, junto a la figura clásica del político-fuente, se localizan nuevos modelos como el político-contertulio, político-celebrity o político-cronista. Así, el análisis realizado verifica la hipótesis establecida: el estilo narrativo del politainment proporciona nuevas actividades comunicativas para los líderes políticos generando nuevos perfiles y funciones, aunque estas sean aún minoritarias respecto a la tradicional del político como fuente de noticias. En estos nuevos roles, las cualidades individuales del político se sitúan por encima de las institucionales, favoreciendo el proceso de personalización propio de una política espectacularizada.

El estudio realizado presenta una propuesta novedosa de categorización de roles del líder político ante el actual ecosistema informativo, que se prodiga en nuevos medios y formatos. El diseño de nuevas investigaciones aplicadas a formatos de politainment distintos a la tertulia política permitirá detectar las nuevas funciones comunicativas que adquieren los políticos y profundizar en la clasificación propuesta. Asimismo, el trabajo descriptivo realizado permite seguir avanzando en el estudio del politainment y sus repercusiones comunicativas en los líderes políticos, estrategias de los partidos e información que adquiere la audiencia.

\section{Referencias bibliográficas}

Abejón, P. (2013). Estado del periodismo de opinión en España: polarización, género y emolumentos. ZER, 18 (34), pp. 93-109. Disponible en: https://www.ehu.eus/ojs/index.php/Zer/article/viewFile/10647/9885

Berrocal, S.; Abad, L.; Cebrián, E. \& Pedreira, E. (2003). La imagen de los partidos políticos en El Informal, CQC y Las Noticias del Guiñol en las elecciones legislativas de 2001. En Berrocal, S. (Ed.), Comunicación política en televisión y nuevos medios. Barcelona: Ariel.

Berrocal, S. \& Quevedo, R. (2014). La representación de los políticos en revistas femeninas de alta gama: Un estudio de caso, Communication Papers, 3 (5), pp. 61-73.

Berrocal, S. (2016). Tendencias en Comunicación Política en el siglo XXI, la consolidación del infoentretenimiento político televisivo. En González-Martínez, R.; Berrocal, S.; Martín de la Guardia, R. \& Pérez-Sánchez, G. Estudios en homenaje al profesor Celso Almuiña. Historia, periodismo y comunicación. Valladolid: Universidad de Valladolid. 
Berrocal, S. (Coord.) (2017). Politainment. La política espectáculo en los medios de comunicación. Valencia: Tirant Humanidades. DOI: 10.5294/pacla.2018.21.1.10

Borrat, H. (1989). El periódico, actor político. Barcelona: Gustavo Gili.

Armentia, J. I. \& Caminos, J. M. (1998). La información: redacción y estructuras. Bilbao: UPV/EHU.

Casero, A. (2009). El control político de la información periodística. Revista Latina de Comunicación Social, 64, pp. 354366. DOI: 10.4185/RLCS-64-2009-828-354-3

Cembrero, I. (31 de enero de 2012). Ahmadinejad presenta la TV iraní en español como un arma de lucha ideológica, El País.

Cesareo, G. (1986). Es noticia. Procesos, fuentes, tecnologías y temas en el aparato informativo. Barcelona: Mitre.

Daymond, C. \& Holloway, I. (2011). Qualitative research methods in Public Relations and Marketing Communications. Londres: Routledge. DOI: 10.4324/9780203846544

De Fontcuberta, M. (1993). La noticia. Pistas para percibir el mundo. Barcelona: Paidós.

Diamond, E.; McKay, M. \& Silverman, R. (1993). Pop goes politics. American Behavioral Scientist, 37 (2), pp. 257-261. DOI: $10.1177 / 0002764293037002013$

Gaspar, A. \& Ibeas, N. (2015). El discurso institucional en tiempos de crisis: análisis del Mensaje de Navidad de Su Majestad el Rey, ZER, 20 (38), pp. 31-48. Disponible en: https://www.ehu.eus/ojs/index.php/Zer/article/view/14778

Habler, J.; Maurer, M. \& Oschatz, C. (2014). Media Logic and political logic online and offline. The case of climate change communication. Journalism Practice, 8 (3), pp. 326-341. DOI: 10.1080/17512786.2014.889451

Halperin, J. (1995). La entrevista periodística: intimidades de la conversación pública. Buenos Aires: Paidós

Kepplinger, H. (2002). Mediatization of politics: Theory and Data. Journal of Communication, 52 (4), pp. 972-986. DOI: $10.1111 /$ j.1460-2466.2002.tb02584.x

Krinppendorff, K. (1990). Metodología de análisis de contenido. Teoría y práctica. Barcelona: Paidós.

Loeb, L. (2017). Politicians on celebrity talk shows. Discourse, Content and Media, 20, pp. 146-156. DOI: 10.1515/ text.2010.026

Mazzoleni, G. \& Schutz, W. (1999). Mediatization of Politics: A Challenge for Democracy? Political Communication, 16 (3), pp. 247-61. DOI: 10.1080/105846099198613

Mercado, M.T. (2005). El infoshow con cámara oculta: ¿investigación periodística o espectáculo? Sala de Prensa, 3.

Quevedo, R. (2017). Entrevistas blandas, comunicación política y nuevos retos. En Berrocal, S. (Coord.). Politainment. La política espectáculo en los medios de comunicación. Valencia: Tirant Humanidades. DOI: 10.5294/pacla.2018.21.1.10

Rebolledo, M. (2017). La personalización de la política: una propuesta de definición para su estudio sistemático. Revista de Comunicación, 16 (2), pp. 147-176. DOI: 10.26441/RC16.2-2017-A7 
Redondo, M. (2011). El sensacionalismo y su penetración en el sistema mediático español, (Tesis doctoral). Universidad de Valladolid.

Rodrigo Alsina, M. (1999). La construcción de la noticia. Barcelona: Paidós.

Salgado, A. (2005). El presentador de noticias: las cualidades necesarias para una comunicación eficaz. Comunicar, 25. DOI: $10.3916 / 25773$

Sánchez-García, P. \& Campos, V. (2017). La tertulia política televisiva como formato de infoentretenimiento. En Berrocal, S. (Coord.), Politainment. La política espectáculo en los medios de comunicación. Valencia: Tirant Humanidades. DOI: 10.5294/pacla.2018.21.1.10

Sánchez-Serrano, Ch. (2005). Tertulias políticas en la radio española. Quién crea la opinión y cómo se produce. Comunicología: indicios y conjeturas, 1 .

Street, J. (2004). Celebrity Politicians: Popular culture and Political Representation, Political Studies Association, 6, pp. 435-452.

Strömbäck, J. \& Esser, F. (2015). Making Sense of Mediatized Politics. Londres: Routledge.

Thusu, D. (2007). Newsasentertainment. The rise ofglobal infotainment.Londres:Sage. DOI: 10.1080/1461670X.2014.897412

Investigación financiada: Esta investigación se ha elaborado en el marco del Proyecto de Investigación I+D+i Politainment en el entorno de la posverdad: nuevas narrativas, clickbait y gamificación» (CSO2017-84472-R), subvencionado por el Ministerio de Economía, Industria y Competitividad del Gobierno de España. 